Tohoku J. exp. Med., 1969, 97, 155-160

\title{
Heparin Treatment of Amniotic Fluid Embolism*
}

\author{
Masahiro Maki, Kyoko Tachita, \\ Yasuyuki Kawasaki and Kazuma Nagasawa
}

\author{
Department of Obstetrics and Gynecology (Prof. S. Shinagawa), \\ Faculty of Medicine, Hirosaki University, Hirosaki
}

\begin{abstract}
From the view-point that amniotic fluid embolism is associated with disseminated intravascular coagulation, platelet thrombi or both, heparin therapy was attempted on a patient with suspected amniotic fluid embolism. The treatment was effective.

The tests for coagulation-fibrinolysis system revealed a sudden and transient prolongation of thrombin clotting time and prothrombin time, and decrease in fibrinogen and platelets during shock. These laboratory findings assured that acute disseminated intravascular coagulation was complicated in this patient. The significance of erythrocyte sedimentation rate in establishing the diagnosis of obstetric hypofibrinogenemia was emphasized.
\end{abstract}

Amniotic fluid embolism is one of the most serious complications in obstetrics. Recent advance in the study of coagulation-fibrinolysis system has suggested that disseminated intravascular coagulation plays an important role in manifestation of clinical signs of amniotic fluid embolism. From this etiological point of view, heparin therapy was indicated to a patient with suspected amniotic fluid embolism, and the treatment was found effective. The case history and the results of coagulation-fibrinolysis assay are presented in this paper.

\section{Methods}

The assay methods for the coagulation-fibrinolysis system were as follows:

(1) Bleeding time by Duke.

(2) Platelet count by Sahli-Fonio.

(3) Prothrombin time by Quick's one stage method.

(4) Thrombin elotting time. ${ }^{1}$

(5) Fibrinogen by a modified method of Ratnoff and Menzie., ${ }^{2,3}$

(6) Plasminogen by caseinolytic activity of euglobulin fraction in the presence of streptokinase. ${ }^{4}$

(7) Whole blood clot lysis time by Ratnoff.

(8) Split products derived from either fibrinogen or fibrin were determined by a simplified method of tanned red cell hemagglutination inhibition immunoassay of Merskey et al. 5,6

Received for publication, November 12, 1968.

* The 18th Report on Pathophysiology of Plasmin System. 


\section{Case Report}

A 22-year-old woman at term, para 1, gravida 3 , and abortus 1 , was admitted at 8 p.m., August 13, 1968, complaining of rupture of the membrane 4 hours before her admission. No particular personal and family histories were obtained. The last menstrual period had been from Nov. 5, 1967, and the pregnancy had been apparently normal except for edema from the end of June to the middle of July, which had disappeared soon after administration of Renese, a preparation of polythiazide

Obstetric examination on admission revealed L.O.A. position of the fetus, 2finger-breadth dilated cervix, the ruptured membrane and flowing out of amniotic fluid. After the admission, the labor became stronger and she was delivered spontaneously of a male infant weighing $3,300 \mathrm{~g}$ with a large volume of amniotic fluid at 11:53 p.m. Methergin (methylergometrin maleate, Sandoz) was injected in a dose of $0.2 \mathrm{mg}$ immediately after the delivery, and the complete placenta was expelled 10 minutes later. Neither abnormal laceration nor abnormal bleeding was noted. Approximately 5 minutes after the placental delivery, she suddenly fell into severe shock with such signs as transient initial cough, indistinct consciousness, dyspnea, breast pain, cyanosis, tachycardia $(150 / \mathrm{min})$ and edematous appearance of the face especially around the lips and eye-lids. The pulse on the radial artery was not palpable and blood pressure unmeasurable.

Dexamethasone (4 mg) and Restamine $(10 \mathrm{mg}$ of diphenhydramine hydrochloride, Kowa) were injected immediately after the onset of shock. Blood sample obtained from the cubital vein was markedly dark, suggesting the presence of hypoxemia. The erythrocyte sedimentation rate (ESR) 'by Westergren's method was lower (almost zero/hour) than that during labor $(34 \mathrm{~mm} / \mathrm{hour}$ ). Such a rapid delay in ESR suggested depletion of fibrinogen, which might have resulted from disseminated intravascular coagulation (cf. Discussion). From the above clinical signs and delayed ESR, amniotic fluid embolism was suspected. Approximately 1,500 units of heparin was given to inhibit further intravascular coagulation. Fifteen minutes after heparin injection, uterine bleeding less than $100 \mathrm{ml}$ was observed. Again $4 \mathrm{mg}$ of dexamethasone was added. From 2:30 a.m. cyanosis and edema disappeared slowly. Blood pressure rose gradually

TABLE 1. Laboratory tests

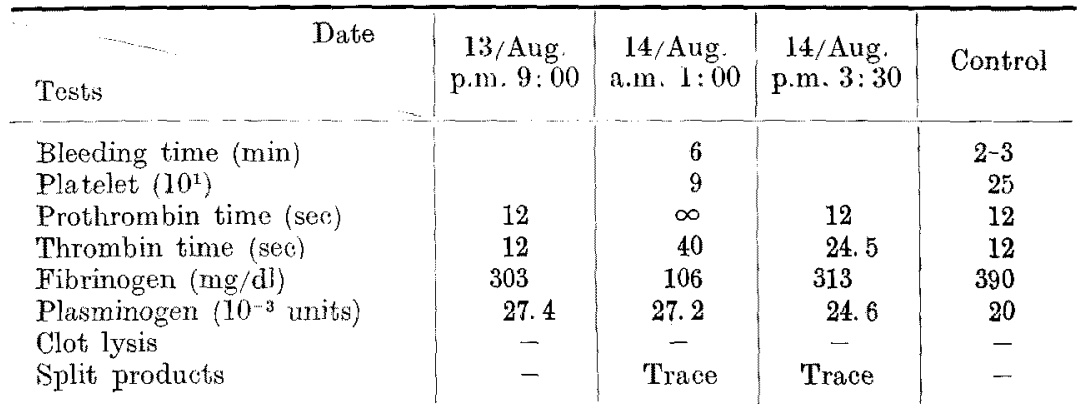


and reached $110-100 \mathrm{~mm} H g$ (max.) before 4 a.m. No oliguria was observed in the course of puerperium. She was discharged 7 days after admission.

The laboratory tests for coagulation-fibrinolysis system are presented in Table 1 , showing decrease in fibrinogen and platelets, and prolonged thrombin clotting time and prothrombin time. There was no detectable fibrinolytic activity.

\section{Discusston}

In 1926 Meyer? published a paper entitled 'Embolis pulmonar amnio-caseosa', which seems to be the first description of the disease entity of amniotic fluid embolism. Since the present concept of amniotic fluid embolism was introduced by Steiner and Lushbaugh ${ }^{8}$ in 1941, numerous clinical and experimental reports have been published. According to Albrechtsen, ${ }^{9}$ the course of amniotic fluid embolism can be divided into 3 phases: shock, hemorrhage and acute renal failure with anuria.

The clinical features of amniotic fluid embolism can be explained by the following processes, some of which may be involved at the same time.

\section{A) Shock in the first phase}

1) Disseminated pulmonary emboli of particulate debris of amniotic fluid.

2) A reflex vascular spasm and an allergic reaction elicited by foreign protein in amniotic fluid.

3) Disseminated intravascular coagulation induced by the trespass of thromboplastin in amniotic fluid into the circulation. However, this is not always certain, because thromboplastin concentration in amniotic fluid is not enough to produce extensive intravascular coagulation.

\section{B) Hemorrhage in the second phase}

Hemorrhage in cases of amniotic fluid embolism may oceur from various causes as follows:

1) Disseminated intravascular coagulation reduces coagulation factors such as fibrinogen, prothrombin, factors V and VIII, and platelets, because these factors are consumed in the course of blood coagulation.

2) Pronounced changes have been also observed in the fibrinolytic system, by which hemorrhagic diathesis is enhanced. Increase in plasmin and activator followed by a decrease in plasminogen are involved. As amniotic fluid itself does not contain detectable plasminogen activator, the elevation of fibrinolytic activity in cases of amniotic fluid embolism may not be the primary change due to invasion of amniotic fluid into the circulation, but the secondary response to the intravascular fibrin clot. Theoretically, hyperplasminemia can produce a coagulation disorder by digestion of fibrinogen and factors V, VIII and XIII. This seems, however, to occur rarely in the circulation, because plasma contains high concentration of antiplasmins, which are enough to neutralize or destroy $5-30$ 
times activated plasminogen in a unit volume of plasma. In various acquired coagulation disorders in obstetrics, we could detect split products derived from only fibrin but not from fibrinogen. ${ }^{10}$ This suggests that the coagulation disorders excepting idiopathic thrombocytopenia in obstetrics may be due to intravascular coagulation with secondary fibrinolysis, but not fibrinogenolysis. Since such split products derived from either fibrinogen or fibrin have an activity to inhibit thrombin action, they enhance hemorrhagic diathesis. In our own case fibrinolytic activity was not detectable. This might be an important reason why hemorrhagic diathesis did not appear even after heparin therapy.

3) Schneider ${ }^{11}$ reported that the incoagulability of circulating blood in patients with isolated amniotic fluid embolism was caused by liberation of heparin from mast cells in the stage of shock, while Baker and Jacob ${ }^{12}$ suggested that the anticoagulant factor was different from heparin.

\section{C) Acute renal failure in the third stage}

This may result from circulatory disturbance in the kidney due to embolism of particulate debris, platelets thrombi, intravascular coagulation and hemorrhagic shock.

From the above pathogenesis of the amniotic fluid embolism, heparin therapy seems to be effective in inhibiting intravascular coagulation and platelet thrombi. Hardaway noted in a dog experiment that heparin prevented intravascular coagulation induced by intravenous injection of trypsin and increased the survival rate. ${ }^{13}$ We also noted that shock and fibrinogen depletion induced by intravenous injection of saline extract of the placenta were greatly reduced by heparin. ${ }^{14}$

In human cases, heparin was once indicated to a patient with leukemia accompanied by intravascular coagulation syndrome, ${ }^{15}$ and successful management of septic abortion by heparin was reported by Pfau et al, ${ }^{16}$ and of dead fetus syndrome by Lerner et al. ${ }^{17}$ and Skødt. ${ }^{18}$

In our own case, such signs as shock, delayed ESR, prolonged coagulation time seemed to be sufficient to suggest amniotic fluid embolism. Therefore, we finally decided to give heparin carefully, the dose being restricted to minimum as compared with that in the usual anticoagulant therapy. The reasons why we used such a small amount of heparin were as follows: (1) We were worried about profuse postpartum hemorrhage, and (2) we considered that a large amount of heparin was not necessary to prevent intravascular coagulation in intact vessels. Fortunately our patient was cured. However, in evaluating the effectiveness of heparin therapy in this case, it must be borne in mind that the condition of the patient suggested rather mild amniotic fluid embolism which might have been spontaneously relieved without heparin therapy. Despite the theoretical and experimental effectiveness of heparin therapy, further experience would be necessary for deciding whether heparin therapy is definitely effective in such a clinical case. It is necessary to use protamine sulfate or polybrene in order to 
neutralize heparin, if bleeding is found to increase.

We would like to emphasize the significance of ESR in establishing the diagnosis of obstetric hypofibrinogenemia. It is quite obvious that fibrinogen content in blood is related closely to the ESR. ${ }^{19}$ Both fibrinogen concentration and ESR usually increase with advance in the stages of pregnancy. The average ESR at term in normal pregnancy reaches $50 \mathrm{~mm} /$ hour by Westergren's method. On the other hand, the ESR is markedly delayed in hypofibrinogenemia as presented in Table 2. An observation period of 15 minutes is enough to decide whether ESR is accelerated or pathologically delayed in pregnancy.

TABLE 2. Erythrocytes sedimentation rate (one hour rate) in patients with obstetric hypofibrinogenemia

\begin{tabular}{|c|c|c|c|c|}
\hline Case No. & Age & Clinical diagnosis & Fibrinogen & ESR \\
\hline 1 & 32 & Abruptio placentae & $36.1 \mathrm{mg} / \mathrm{dl}$ & $4 \mathrm{~mm}$ \\
\hline 2 & 30 & Postpartum hemorrhage & 60.0 & 12 \\
\hline 3 & 33 & Abruptio placentae & 72.0 & 5 \\
\hline 4 & 43 & 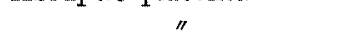 & 59.4 & 2 \\
\hline 5 & 34 & $"$ & * & 8 \\
\hline 11 & 28 & $"$ & 75.0 & 10 \\
\hline 12 & 28 & $"$ & 58.8 & 6 \\
\hline 13 & 20 & Postpartum hemorrhage & 40.0 & 10 \\
\hline 14 & 27 & Amniotic fluid embolism & $*$ & 14 \\
\hline 15 & 29 & Abruptio placentae & 60.0 & 9 \\
\hline 16 & 27 & (n) & 10.0 & 11 \\
\hline 20 & 34 & $"$ & * & 4 \\
\hline \multirow[t]{2}{*}{21} & 33 & Postpartum hemorrhage & 67.0 & 10 \\
\hline & & Jormal pregnancy at term & 390 & 50 \\
\hline
\end{tabular}

* Fibrinogen was not determined and the diagnosis was made only from clinical signs.

\section{References}

1) Maki, M. Differentiation between fibrinogenolysis and fibrinolysis products induced by plasmin. Acta haemat. Jap., 1967, 30, 267-275.

2) Ratnoff, O.D. \& Menzie, C. A new method for the determination of fibrinogen in small samples of plasma. J. Lab. clin. Med., 1951, 37, 316-320.

3) Maki, M., Kikuchi, E. \& Sato, T. A supplementary study of the quantitative determination of fibrinogen in blood plasma. Nippon Sanka Fujinha Gakkai Zasshi (Jap.), 1961, 13, 1081-1084.

4) Maki, M. Supplementary note on the euglobulin fraction method as a tool of clinical plasmin research. Tohoku J. exp. Med., 1963, 81, 179-187.

5) Merskey, C., Kleiner, G.J. \& Johnson, A.J. Quantitative estimation of split products of fibrinogen in human serum, relation to diagnosis and treatment. Blood, 1966, $28,1-18$.

6) Maki, M., Sato, S. \& Mori, I. Clinical significance of detection of fibrinogen and its derivatives by tanned red cell hemagglutination inhibition immunoassay. Sogo Rinsho (Jap.), 1968, 17, 168-173.

7) Meyer, J.R. Embolis pulmonar amnio-caseosa. Brasil-Méd., 1926, 2, 301, cited in 9.

8) Steiner, P.E. \& Lushbaugh, C.C. Maternal pulmonary embolism by amniotic fluid as a cause of obstetric shock and unexpected death in obstetrics. J. Amer. med. Assc., 1941, 117, 1245-1254. 
9) Albrechtsen, O.K. Hemorrhagic disorders following amniotic fluid embolism. Clin. Obstet. Gynec., 1964, 7, 361-371.

10) Maki, M. \& Sato, S. Etiology of acquired hypofibrinogenemia. Rinsho Ketsueki (Jap.), $1968,2,298-304$.

11) Schneider, C.L. Coagulation defects in obstetric shock: Meconium and heparin; fibrin embolism and defibrination. Amer. J. Obstet. Gynec., 1963, 87, 48-55.

12) Baker, S.J. \& Jacob, E. A haemorrhagic disorder in pregnancy due to an "anticoagulant" preventing the conversion of fibrinogen to fibrin. J. clin. Path., $1960,13,214-219$.

13) Hardaway, R.M. The role of intravascular clotting in the etiology of shock. Ann. Surg., 1962, 155, 325-338.

14) Maki, M., Nagayama, M. \& Mori, I. Indication or contraindication in clinical use of thromboplastin preparations as hemostatic agents. Nippon Iji Shinpo (Jap.), $1967,2263,16-18$.

15) Baker, W.G., Bang, N.U., Nachman, R.L., Raafat, F. \& Horowitz, H.I. Hypofibrinogenemic hemorrhage in acute myelogenous leukemia treated with heparin. Ann. int. Med., 1964, 61, 116-123.

16) Pfau, P., Lasch, H.G. \& Gunther, O. Sanarelli-Shwartzman Phänomenon bei febrilen Fehlgeburten und schweren Schock und Blutungszuständen in der Geburtshilfe, Gynecologia, 1960, 150, 17-33.

17) Lerner, R., Margolin, M., Slate, W.G. \& Rosenfeld, H. Heparin in the treatment of hypofibrinogenemia complicating fetal death in utero. Amer. J. Obstet. Gynec., 1967, 97, 373-378.

18) Skødt, P. Intrauterine foetal death with hypofibrinogenemia, coagulation studies in a case treated with heparin. Acta obstet. gynec. scand., 1967, 46, 59-77.

19) Shinagawa, S., Mari. M., Kikuchi, I., Okuyama, T., Matsumura, R. \& Sasaki, K. Erythrocytes sedimentation rate as a simple bedside procedure available for the suspection of obstetrical hypofibrinogenemia. J. Jap. obstet. gynec. Soc., 1964, 11, 251-254. 